\title{
A New Concept of Scallop Screens for Reactors of Refining
}

\author{
F. Pradel ${ }^{1}$, Y. Meimon ${ }^{1}$, A. Blanchon², S. Lorgeou ${ }^{2}$ and H. Naderi² \\ 1 Institut français du pétrole, 1 et 4, avenue de Bois-Préau, 92852 Rueil-Malmaison Cedex - France \\ 2 Johnson, Zone industrielle, 86350 Availles-en-Châtellerault - France \\ e-mail: francis.pradel@ifp.fr - yves.meimon@ifp.fr - ablancho@usffiltration.com - slorgeou@usffiltration.com - hnaderi@usffiltration.com
}

Résumé - Nouveau concept de caisson pour les réacteurs de raffinage - Dans un réacteur de reformage catalytique à lit mobile, le catalyseur est contenu dans l'annulaire constitué de deux paniers concentriques en grille Johnson. Une innovation introduite par Johnson réside dans le remplacement du panier externe par une succession de caissons d'un nouveau type de scallop, appelée OptiMiser ${ }^{\mathrm{TM}}$, placés côte à côte. Le panier extérieur du réacteur devient ainsi modulaire facilitant la construction du réacteur ainsi que sa maintenance, tout en sauvegardant l'efficacité du procédé pour le débit et la perte de charge du gaz.

L'étude technique de cette innovation a été confiée par Johnson à l'IFP.

Dans un premier temps, grâce à la théorie de l'homogénéisation, un modèle de plaque anisotrope élastique a été développé pour remplacer une grille Johnson, constituée de fils soudés à des raidisseurs. Ce modèle a été inséré dans un code de calcul de structure par la méthode des éléments finis $\left(\mathrm{ABAQUS} \mathrm{T}^{\mathrm{TM}}\right)$. Le modèle a été validé grâce à une série d'essais de traction, cisaillement et de flexion en quatre points réalisés sur des éprouvettes de grille Johnson. Dans une dernière étape, des essais de compression et de flexion en quatre points ont été réalisés sur des prototypes de caisson. Ces essais de structure ont été calculés par éléments finis en utilisant le modèle de plaque équivalente développé pour la grille Johnson.

À l'issue de cette démarche, on a pu considérer que le modèle de grille a été suffisamment validé pour être utilisé dans l'étude de réacteurs réels en condition de fonctionnement.

Mots-clés : réacteur à lit mobile, reformage catalytique, grille Johnson, homogénéisation, essais mécaniques, validation de modèle, modèle élastique de plaque anisotrope.

\footnotetext{
Abstract - A New Concept of Scallop Screens for Reactors of Refining - In a moving bed reactor for catalytic reforming, the catalyst is enclosed inside an annulus constituted by two concentric baskets made of Johnson grid. An innovation introduced by Johnson consists in the replacement of the outer basket by a succession of panels of a new type of scallop, called OptiMiser ${ }^{\mathrm{TM}}$, set side by side. So, the outer basket of the reactor becomes modular, facilitating the building of the reactor as well as its maintenance, while protecting the efficiency of the process for the gas flow and the pressure drop.

Johnson entrusted the technical study of this innovation to IFP.

At first, thanks to the theory of the homogenization, a model of elastic anisotropic plate was developed to replace Johnson grids, assembly of wires welded to stiffener bars, named rods. This model was inserted into a finite element method (FEM) code designed for structure calculations (ABAQUS $\left.{ }^{\mathrm{TM}}\right)$. The model was first validated thanks to a series of tensile, shear and bending tests performed on grid samples. In a
} 
second step, compression and bending tests were run on prototypes of scallop panel. These structure tests were also calculated by using the FEM with the equivalent plate model developed for the Johnson grid. As a conclusion, the model of grids was validated and then approved for further studies of real reactors in operating conditions.

Keywords: moving bed reactor, catalytic reforming, Johnson grid, homogenization, mechanical tests, model validation, elastic model for anisotropic plate.

\section{NOTATIONS}

\section{Latin Letters}

$i, j \quad$ indices with a value of 1,2 or 3

$e_{1}, e_{2}, e_{3}$ base space frame where $e_{3}$ direction is perpendicular to the grid

$u, v \quad$ displacements in the plane of the grid

$w \quad$ displacement normal to the grid

$f_{, i} \quad$ differentiation of $f(x)$ with respect to the $i^{\text {th }}$ component of vector $x$ : $\left(\frac{\partial f}{\partial x_{i}}\right)$

$$
N_{\alpha \beta}=\int_{-h / 2}^{h / 2} \sigma_{\alpha \beta} d e \quad \begin{aligned}
& \text { membrane force per unit length in } \\
& \text { an homogeneous plate }(\mathrm{N} / \mathrm{m})
\end{aligned}
$$$$
M_{\alpha \beta}=\int_{-h / 2}^{h / 2} x_{3} \sigma_{\alpha \beta} d e \begin{aligned}
& \text { bending moment per unit length in } \\
& \text { an homogeneous plate }(\mathrm{N} \cdot \mathrm{m} / \mathrm{m})
\end{aligned}
$$

$E_{\text {wire }} \quad$ Young modulus of the wires

$E_{\text {rod }} \quad$ Young modulus of the rods

$G_{\text {wire }} \quad$ shear modulus of the wires

$G_{\text {rod }} \quad$ shear modulus of the rods

$S_{\text {wire }} \quad$ wire section

$S_{\text {rod }} \quad$ rod section

$l_{\text {wire }} \quad$ wire length between two rods from axis to axis

$l_{\text {rod }} \quad$ rod length between two wires from axis to axis

$I_{1}^{\text {wire }} \quad$ wire inertia in the normal direction to the plate

$I_{1}^{\text {rod }} \quad$ rod inertia in the normal direction to the plate

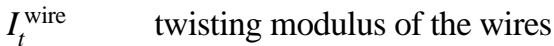

$I_{t}^{\text {rod }} \quad$ twisting modulus of the rods.

\section{Greek letters}

$\alpha, \beta \quad$ indices taking a value of 1 or 2

$\sigma \quad$ Cauchy stress tensor

$\varepsilon_{\alpha \beta} \quad$ component of the plane strain tensor of a plate

$\kappa_{\alpha \beta}=w_{, \alpha \beta}$ component of the curvature tensor of a plate.

\section{INTRODUCTION}

Among the processes of refining, the continuous catalytic reforming process, which consists in radial gas injection across a catalyst moving bed, allows to increase the octane rate of gas pool. The endothermic chemical reaction develops towards $500^{\circ} \mathrm{C}$ in reactors, set in a row (Fig. 1), whose internal annulus is filled with catalyst circulating slowly from one reactor to the other one. The gas load circulates between the walls of these annulus, which are generally made of Johnson grids. Figure 2 [1] shows that, according to the design, these walls shape a basket in one piece (Fig. 2a) or an assemblage of Johnson scallop screens (Fig. 2b).

They can be subjected to significant efforts like thermal cycles during the operations of maintenance. These baskets may be damaged after a while of functioning. Then their replacement is required, which is an expensive operation, especially in the case of the outer basket.

A new concept of outer basket, called OptiMiser ${ }^{\mathrm{TM}}$, was developed and Johnson and studied by IFP. The innovation consists in replacing this basket in one piece by a set of modular panels put side by side in order to contain the catalyst in the reactor (Fig. 3). Each panel, termed Johnson OptiMiser ${ }^{\mathrm{TM}}$ screen, is a structure composed of Johnson grids and steel sheets.

The advantage of this concept is important when the reactor is set up, but also for the reactor maintenance. Compared to the classic concept of scallops, the new system should allow a better control of the catalyst motion on the grid surface.

The objectives of this article is to present the study for the validation of this new reactor basket concept and to develop the associated method of engineering. It requires an experimental study of the panel behavior and a specific modeling of the Johnson grid allowing to estimate the matrix of the elastic stiffness.

\section{METHODOLOGY OF THE STUDY}

The study took place in several stages (Fig. 4) which can be summarized in two major steps:

- To replace a Johnson grid by an equivalent elastic plate, a model was developed thanks to the technique of homogenization. Mechanical experiments on samples of grids were conducted to validate the model.

- This model was implemented into a finite element method (FEM) computation code to estimate the behavior of one panel. Mechanical experiments on panels were also conducted to validate the structural modeling. 


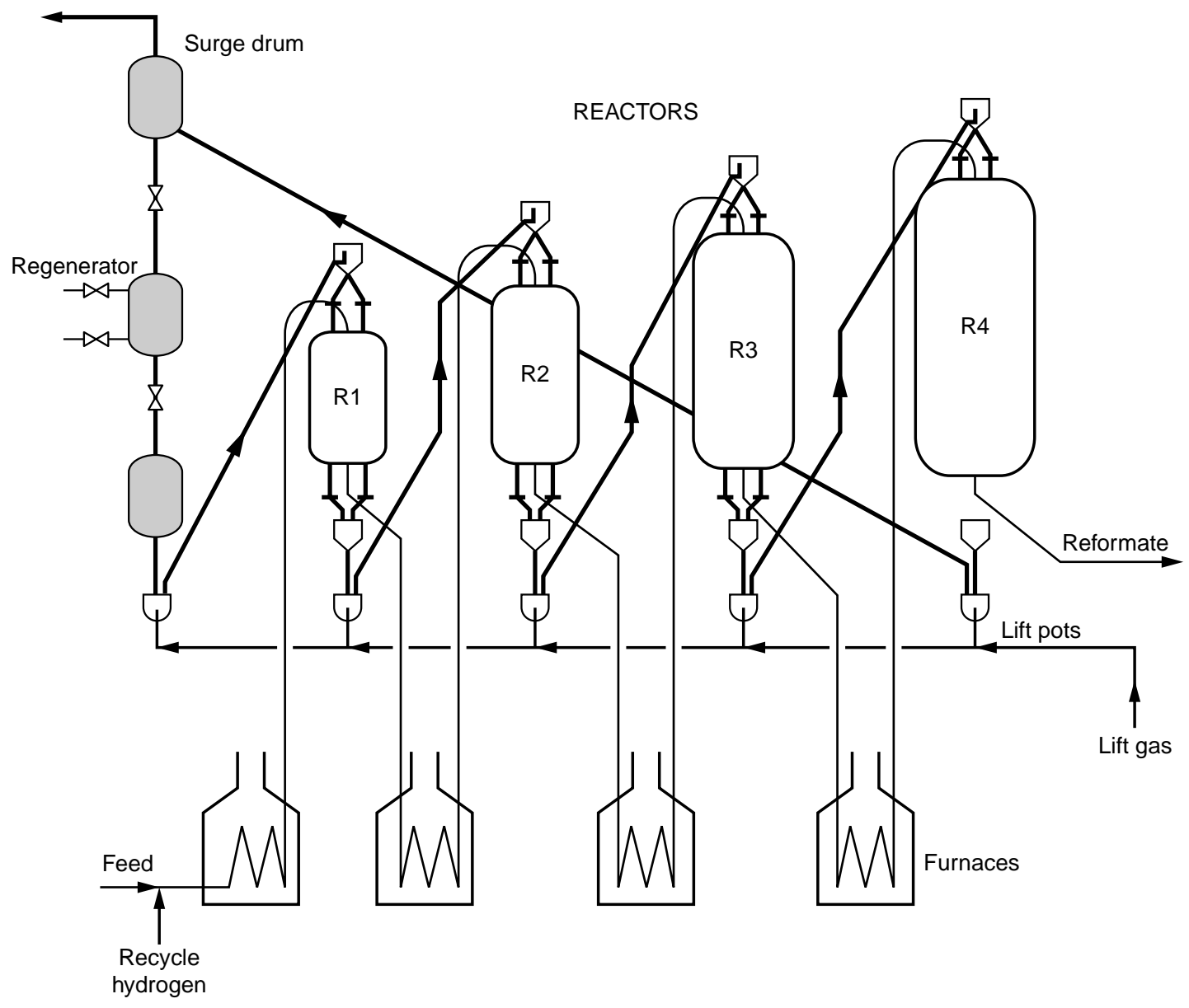

Figure 1

Sketch of a chain of reactors for the process of catalytic reforming.
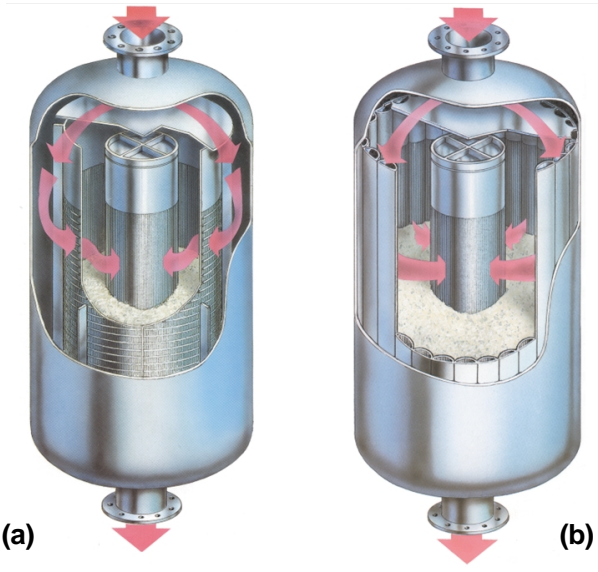

(b)

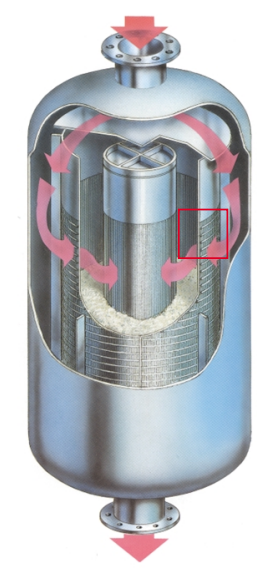

Replaced by
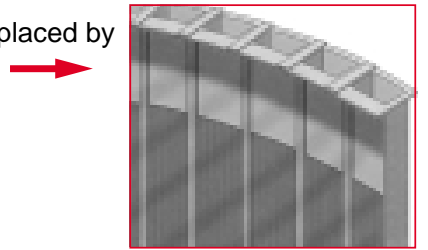

Figure 3

New concept OptiMiser ${ }^{\mathrm{TM}}$ of the outer basket composed of Johnson grid-steel sheet panels. 


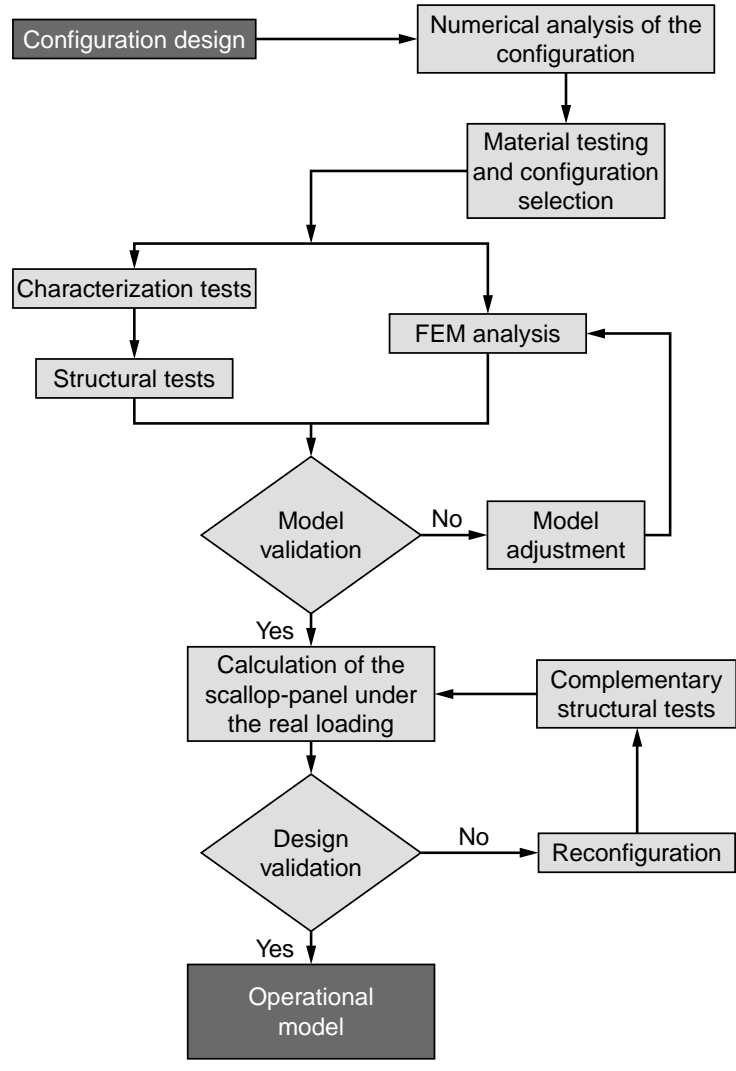

Figure 4

Flowchart of the study.
Once validated, the model can be used to calculate the behavior of one panel under extreme loading, typical of what could happen inside a reactor. Then, the method could be used to optimize the design of a panel.

In fact, a specific methodology (Fig. 4) was adopted in order to optimize the cost of the study. First, we supposed that modeling a Johnson grid by using a theoretical equivalent plate was a correct assumption. Then, a prototype panel was designed by using this model and built. This implied the choice of the Johnson grid type. The grid model was validated and adjusted by considering the results of the tests performed on grid samples and on panels. The final model was applied to the prototype panel. A new panel configuration should be built and tested mechanically, only if the initial configuration failed to be resistant enough.

\section{JOHNSON GRIDS MODELING}

The new technology introduces "structurally" composite modules mixing Johnson grids with steel sheets. A sheet can be modeled by using the classic theory for isotropic plates. Besides, thanks to a simplification of the real assemblage of a Johnson grid, a theory of the homogenization within the framework of the elasticity in small displacements allows to build an anisotropic plate equivalent to the grid. This simplification is needed to obtain tractable calculations. To validate the final model, mechanical tests must be performed on samples of grids.

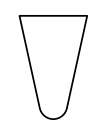

90

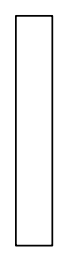

Rod

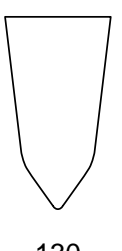

130

(a)

Figure 5

Sketch of the grid pattern.

(a) shapes of rod and wires; (b) grid pattern.

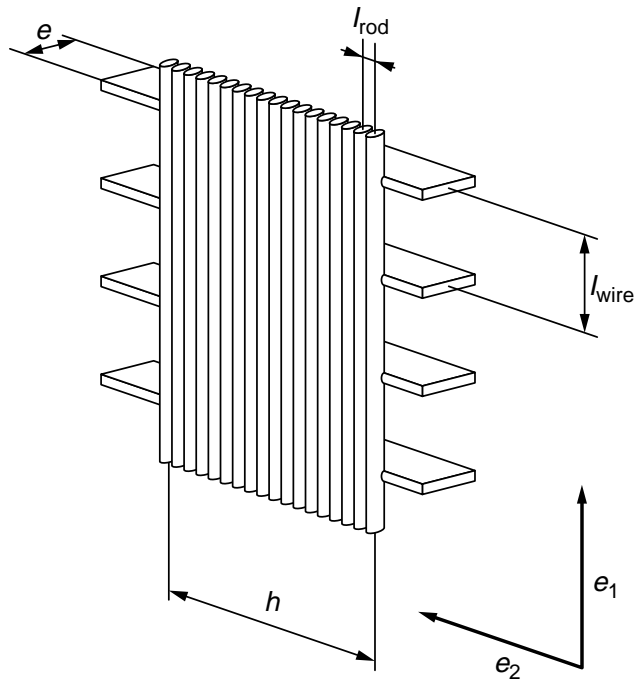

(b) 


\subsection{Description of Johnson Grids}

A Johnson grid is composed of two types of beams. The first type corresponds to a very slender and flexible beam, called wire. The second type, called rod, has a more important section for assuming the function of stiffener. The constitutive material of the wires and the rods is steel which is supposed to have a Young modulus of $199000 \mathrm{MPa}$ according to the "ASME II-part D" recommendations (series 300 steel at $20^{\circ} \mathrm{C}$ ). In every calculation presented hereafter, this value of the steel Young modulus will be used together with a Poisson's ratio of 0.3 .

Two types of wire were used: the "90" wire and the "130" wire according to the Johnson specifications [1]. Their sections have a shape close to an isosceles triangle (Fig. 5a). The "90" wire (respectively "130") has a section of $5.61 \mathrm{~mm}^{2}$ $\left(15 \mathrm{~mm}^{2}\right)$ and a beam inertia of $5.18 \mathrm{~mm}^{4}\left(42.16 \mathrm{~mm}^{4}\right)$ in the parallel direction to the triangle base and $1.52 \mathrm{~mm}^{4}$ $\left(8.99 \mathrm{~mm}^{4}\right)$ in the direction of the triangle height.

Rods correspond to beams of rectangular section $(25 \mathrm{~mm}$ over $3 \mathrm{~mm}$ ) and have an inertia of $3906 \mathrm{~mm}^{4}$ in the direction of the small width of the section and $56.25 \mathrm{~mm}^{4}$ in the other direction.

To build a grid, the wires are welded electrically perpendicularly to the rods (Fig. 5b).

The grid (Fig. 5b) is characterized by a cross-shaped basic pattern paving periodically all its surrounding space. The basic pattern is described by the spacing between axes of the weldings. The spacing $l_{\text {wire }}$ is the length of wire between the axes of two consecutive rods, according to the direction $e_{1}$ (Fig. 5b). The spacing $l_{\text {rod }}$ is the length of rod between two consecutive wires, in the direction $e_{2}$. Two shapes of grids were studied:

- "90" wire spaced out of $l_{\text {wire }}=25.4 \mathrm{~mm}$ with rods spaced out of $l_{\text {rod }}=2.99 \mathrm{~mm}$.

- "130" wire spaced out of $l_{\text {wire }}=38.1 \mathrm{~mm}$ with rods spaced out of $l_{\text {rod }}=4 \mathrm{~mm}$.

\subsection{Homogenization of the Grid}

It is necessary to homogenize the grid in order to obtain an equivalent continuous material whose constitutive equation can be inserted into a FEM software for structure calculation. For that purpose, several mechanical conceptual models of a grid are possible. A representation using bars was developed by [2]. Here a discrete approach is introduced with the use of beams.

Every portion of beam (wire, rod) between two welded butts is seen as two particles located at these points and connected each other by a equation of interaction. The mechanical action of the beams is then replaced by the interaction equation involving the kinematics of translation and rotation of the connected particles.
The retained interaction equation is related to EulerBernouilli beam. The basic cross-shaped pattern retained for the grid allows to identify a "main" particle on which the whole mechanical problem is going to be summarized by writing the equations of balance for this particle (force, couple).

These equations correspond to algebraic equations whose unknowns are the kinematics of the particle. The method of homogenization is initiated on the basis of this discrete mechanical problem. The keystones of the development are:

- A stage of dimensional analysis is performed in order to compare the various implied kinematics (rotation, translation). The mechanical problem is set on a reference geometry without dimensions always identical whatever the size ratio between the overall grid and the basic pattern is. The perception of the lengths is not supposed identical in all the directions: the displacements in the grid plane are associated with the side $(h)$ of the grid while those perpendicular to the grid are associated with a length $(e)$ linked to the section of the beams constituting the grid. A dimensionless system of algebraic equations for the discrete unknowns appear as a result of this analysis.

- The values of the translations and the rotations are then supposed to arise from continuous fields. A continuous field of translation and a continuous field of rotation is given to the particle of the basic pattern. Every algebraic equation is transformed into a differential equation by expressing, thanks to Taylor expansions, the kinematics of neighboring particles with those of the "main" particle considered for the balance. It could be noticed that Taylor expansions of the dimensionless kinematics give expansions according to the asymptotic scale. Details can be found in [3].

- The last step consists in using the asymptotic expansion for every vector field (rotation, translation) to make the system of differential equations easier to solve. Six differential equations with two unknown vector fields constitute the obtained system. By collecting the powers of the asymptotic expansion, a series of chained mechanical problems is obtained. The series of problems is stopped at the wanted order. By writing the conditions of compatibility of the systems, the macroscopic equations of balance show up. All the details of this type of resolution are available in [4].

In the case of the studied grid, different orders of magnitude are used to obtain the main terms of the asymptotic expansions for the equations of balance (forces or couples).

So, by supposing that the wires are in the $e_{1}$-direction and the rods in the $e_{2}$-direction, the following system of equations is obtained, taking into account the anisotropy of the grid. 
where:

$$
\left\{\begin{array}{l}
\frac{k_{n_{1}}^{\text {rod }} l_{\text {rod }}}{l_{\text {fil }}}\left(1-\frac{k_{n_{1}}^{\text {wire }} l_{\text {rod }}^{2}}{k_{n_{1}}^{\text {rod }} l_{\text {rod }}^{2}+k_{n_{1}}^{\text {wire }} l_{\text {wire }}^{2}}\right) u_{, 22}+\frac{k_{t}^{\text {wire }} l_{\text {wire }}}{l_{\text {rod }}} u_{, 11}+\frac{l_{\text {rod }} l_{\text {wire }} k_{n_{1}}^{\text {rod }} k_{n_{1}}^{\text {wire }}}{k_{n_{1}}^{\text {rod }} l_{\text {rod }}^{2}+k_{n_{1}}^{\text {wire }} l_{\text {wire }}^{2}} v_{, 12}=0 \\
\frac{k_{n_{1}}^{\text {fil }} l_{\text {wire }}}{l_{\text {rod }}}\left(1-\frac{k_{n_{1}}^{\text {wire }} l_{\text {wire }}^{2}}{k_{n_{1}}^{\text {rod }} l_{\text {rod }}^{2}+k_{n_{1}}^{\text {wire }} l_{\text {wire }}^{2}}\right) v_{, 11}+\frac{k_{t}^{\text {rod }} l_{\text {rod }}}{l_{\text {wire }}} v_{, 22}+\frac{l_{\text {rod }} l_{\text {fil }} k_{n_{1}}^{\text {rod }} k_{n_{1}}^{\text {wire }}}{k_{n_{1}}^{\text {rod }} l_{1}^{2}+k_{n_{1}}^{\text {wire }} l_{\text {wire }}^{2}} u_{, 12}=0 \\
\frac{k_{\phi}^{\text {rod }} l_{\text {rod }}}{l_{\text {wire }}} w_{, 2222}+\frac{k_{\phi}^{\text {wire }} l_{\text {wire }}}{l_{\text {rod }}} w_{, 1111}+\left(\frac{k_{\theta}^{\text {wire }} l_{\text {wire }}}{l_{\text {rod }}}+\frac{k_{\theta}^{\text {rod }} l_{\text {rod }}}{l_{\text {wire }}}\right) w_{, 1122}=0
\end{array}\right.
$$

$$
\begin{aligned}
& k_{t}^{\text {wire }}=\frac{E_{\text {wire }} S_{\text {wire }}}{l_{\text {wire }}}, \quad k_{n_{1}}^{\text {wire }}=\frac{12 E_{\text {wire }} I_{1}^{\text {wire }}}{l_{\text {wire }}^{3}}, \quad k_{\phi}^{\text {wire }}=\frac{E_{\text {wire }} I_{1}^{\text {wire }}}{l_{\text {wire }}}, \quad k_{\theta}^{\text {wire }}=\frac{G_{\text {wire }} I_{t}^{\text {wire }}}{l_{\text {wire }}} \\
& k_{t}^{\text {rod }}=\frac{E_{\text {rod }} S_{\text {rod }}}{l_{\text {rod }}}, \quad k_{n_{1}}^{\text {rod }}=\frac{12 E_{\text {rod }} I_{1}^{\text {rod }}}{l_{\text {rod }}{ }^{3}}, \quad k_{\phi}^{\text {rod }}=\frac{E_{\text {rod }} I_{1}^{\text {rod }}}{l_{\text {rod }}}, \quad k_{\theta}^{\text {rod }}=\frac{G_{\text {rod }} I_{t}^{\text {rod }}}{l_{\text {rod }}}
\end{aligned}
$$

These values correspond to parameters involved in the writing of the behavior of Euler-Bernoulli beams only loaded at their extremities.

The obtained modeling corresponds to a theory of anisotropic Love-Kirchhoff plate [5]. The equation for the bending represents a generalization of the result obtained for grids in [5].

The main difference compared to previous similar works $[3,6]$ lies in the dimensional analysis step which makes appear various characteristic lengths of the grid. Indeed, the previous works were focused on the homogenization of grid under plane strain conditions. Here, following the example of works made on continuous medium [7], the study of the outof-plane bending is approached within the framework of the discrete media, which constitutes the originality of the homogenization method.

\subsection{Equivalent Continuous Model}

Notations and frames required to characterize a plate are shown in Figure 6.

An anisotropic plate is constituted here by an anisotropic elastic material. As in [5], an orthotropic material is considered, which owns at least three planes of material symmetry. The principal directions of the plane stresses are in the $\left(e_{1}, e_{2}\right)$ plane. Once, the plate theory is set up, the generalized constitutive equation yields:

$$
\left[\begin{array}{l}
N_{11} \\
N_{22} \\
N_{12} \\
M_{11} \\
M_{22} \\
M_{12}
\end{array}\right]=[C] \cdot\left[\begin{array}{c}
\varepsilon_{11} \\
\varepsilon_{22} \\
2 \varepsilon_{12} \\
\kappa_{11} \\
\kappa_{22} \\
\kappa_{12}
\end{array}\right]
$$

where:

$$
\begin{aligned}
& \varepsilon_{11}=u_{, 1} \quad \varepsilon_{22}=v_{, 2} \quad \varepsilon_{12}=\frac{1}{2}\left(u_{, 2}+v_{, 1}\right) \\
& \kappa_{11}=w_{, 11} \quad \kappa_{22}=w_{, 22} \quad \kappa_{12}=w_{, 12} \\
& {[C]=\left[\begin{array}{cccccc}
C_{11} & C_{12} & 0 & & & \\
C_{12} & C_{22} & 0 & & 0 & \\
0 & 0 & C_{33} & & & \\
& & & D_{11} & D_{1} & 0 \\
& 0 & & D_{1} & D_{22} & 0 \\
& & & 0 & 0 & 2 D_{12}
\end{array}\right]}
\end{aligned}
$$

When using a FEM software like ABAQUS ${ }^{\text {TM }}$ [8], the constitutive equation matrix $[C]$ can be implemented straightforwardly.

The balance of a plate decomposes into a balance equation in the plate plane (or membrane):

$$
\operatorname{div}_{2} \underline{\underline{N}}_{2}+\underline{f}_{2}=0
$$

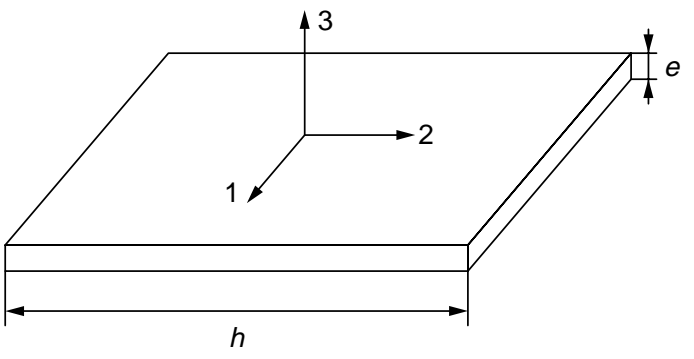

Figure 6

Representation of a plate 
where the index 2 means that the equation is written for two dimensions in the $\left(e_{1}, e_{2}\right)$ plane, $f_{2}$ is the tangential vector of the surface loading, and into a balance of couple (or bending):

$$
\frac{\partial^{2} M_{11}}{\partial x_{1}{ }^{2}}+2 \frac{\partial^{2} M_{12}}{\partial x_{1} \partial x_{2}}+\frac{\partial^{2} M_{22}}{\partial x_{2}{ }^{2}}=q
$$

When injecting the kinematics in (5), a classic Navier's Equation is obtained:

$$
D_{11} \frac{\partial^{4} w}{\partial x_{1}{ }^{4}}+2 H \frac{\partial^{4} w}{\partial x_{1}{ }^{2} \partial x_{2}{ }^{2}}+D_{22} \frac{\partial^{4} w}{\partial x_{2}{ }^{4}}=q
$$

where $w$ is the perpendicular displacement of the plate, $H$ is worth $D_{1}+2 D_{12}$ and $q$ is the normal component of the surface loading applied to the plate.

Thanks to the method of homogenization described in Section 2.2, the assemblage of beams, at the microscopic level, gives a plate at the macroscopic level. The underlying hypotheses correspond to the substitution of the wires and the rods by beams of Euler-Bernoulli type perfectly and perpendicularly clamped at their neutral fibers. The strong anisotropy of the grid results in a negligible Poisson effect in the equivalent plate: $C_{12} \approx 0$ and $D_{1} \approx 0$. By indicating respectively by $t$ and $r$ the direction of the wires and the rods, the constitutive equation for the equivalent plate to the Johnson grid can be written as:

$$
\begin{aligned}
& {\left[\begin{array}{l}
N_{t t} \\
N_{r r} \\
N_{t r}
\end{array}\right]=\left[\begin{array}{ccc}
C_{t t} & 0 & 0 \\
0 & C_{r r} & 0 \\
0 & 0 & C_{t r}
\end{array}\right] \cdot\left[\begin{array}{l}
\varepsilon_{t t} \\
\varepsilon_{r r} \\
\varepsilon_{t r}
\end{array}\right]} \\
& {\left[\begin{array}{l}
M_{t t} \\
M_{r r} \\
M_{t r}
\end{array}\right]=\left[\begin{array}{ccc}
D_{t t} & 0 & 0 \\
0 & D_{r r} & 0 \\
0 & 0 & D_{t r}
\end{array}\right] \cdot\left[\begin{array}{l}
\kappa_{t t} \\
\kappa_{r r} \\
\kappa_{t r}
\end{array}\right] .}
\end{aligned}
$$

with the following coefficients depending on the beams characteristics:

$$
\begin{aligned}
& C_{t t}=\frac{E_{\text {wire }} S_{\text {wire }}}{l_{\text {rod }}} \quad C_{r r}=\frac{E_{\text {rod }} S_{\text {rod }}}{l_{\text {wire }}} \\
& C_{t r}=12 \frac{E_{\text {wire }} E_{\text {rod }} I_{1}^{\text {wire }} I_{1}^{\text {rod }}}{E_{\text {wire }} I_{1}^{\text {wire }} l_{\text {rod }}^{2}+E_{\text {rod }} I_{1}^{\text {rod }} l_{\text {wire }}^{2}} \\
& D_{t t}=\frac{E_{\text {wire }} I_{1}^{\text {wire }}}{l_{\text {rod }}} D_{r r}=\frac{E_{\text {rod }} I_{1}^{\text {rod }}}{l_{\text {wire }}} \\
& D_{t r}=\frac{1}{2}\left(\frac{G_{\text {wire }} I_{t}^{\text {wire }}}{l_{\text {rod }}}+\frac{G_{\text {rod }} I_{t}^{\text {rod }}}{l_{\text {wire }}}\right)
\end{aligned}
$$

In the case of the grids studied for the new panel design, the theoretical modeling yields the following values (SI system): - for "90" wires:

$$
C_{t t}=3.7310^{8}, C_{r r}=5.8810^{8}, C_{t r}=1.8810^{6}
$$

$$
D_{t t}=3.0610^{4}, D_{r r}=3.4410^{2}, D_{t r}=1.2110^{4}
$$

- and for "130" wires:

$$
\begin{aligned}
& C_{t t}=8.2510^{8}, C_{r r}=3.9210^{8}, C_{t r}=4.0310^{6}, \\
& D_{t t}=2.0410^{4}, D_{r r}=2.3210^{3}, D_{t r}=9.0410^{3}
\end{aligned}
$$

The unit for the coefficients from $C_{\mathrm{tt}}$ to $C_{\mathrm{tr}}$ is $\mathrm{N} / \mathrm{m}$ and the unit for the coefficients from $D_{\mathrm{tt}}$ to $D_{\mathrm{tr}}$ is $\mathrm{N} \cdot \mathrm{m}$.

\subsection{Experimental Characterization of Johnson Grid}

\subsubsection{Experimental Device}

Mechanical tests of tension-compression, shearing and bending were performed on grid samples to characterize Johnson grids and estimate the pertinence of the model developed.

Mechanical loads (maximum load of $50 \mathrm{kN}$ ) were applied with an INSTRON 8500+ hydraulic press. Displacements were measured with two INSTRON 2620 extensometers, fixed to the Johnson grid. The extensometers were used to get rid of the press crossbar displacement measurement. They have a stroke of $\pm 5 \mathrm{~mm}$ around an initial length (25 or $50 \mathrm{~mm})$.

Figure 7 shows the two types of samples used for the inplane characterization of the grid. A sample was composed of a Johnson grid welded at each end to a steel plate. These plates were useful to fix the sample in the clamps of the testing machine. The strong anisotropy of the grids in the directions of rods and wires requires tension tests in these two directions.

For the out-of-plane bending part of the constitutive equation, rectangular samples $(625 \mathrm{~mm}$ over $300 \mathrm{~mm})$ of Johnson grids were used.

To validate the convergence of the method of homogenization into an homogeneous plate, samples containing a variable number of wires and rods were built. They contained from ten to more than eighty wires and from five to fourteen rods.

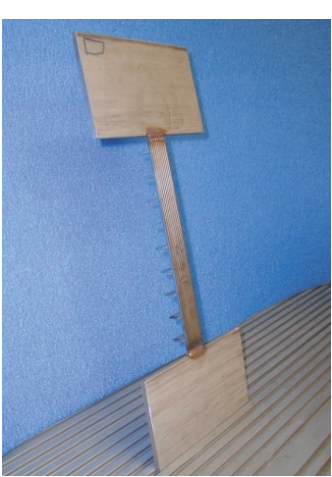

(a)

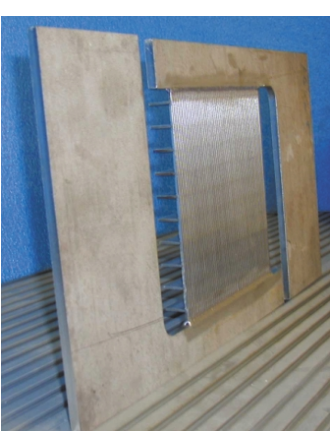

(b)
Figure 7

Grid samples.

a) sample for tension test; b) sample for shear test. 
Tension tests were also performed on isolated wires and rods. This resulted in a rod Young modulus of $180000 \mathrm{MPa}$ slightly different from the ASME recommendation (199000 MPa). A larger difference was obtained for the wire Young modulus. In the calculations presented in this paper, the retained modulus for the steel was always the reference modulus recommended by the ASME.

\subsubsection{Tension Behavior of a Johnson Grid}

The principle of the uniaxial tension test is to place between the press clamps a sample of Johnson grid and to move the bottom clamp vertically downward at a constant speed $(0.1 \mathrm{~mm} / \mathrm{min})$ whereas the upper clamp stays motionless. The displacement, $\delta$, and the applied force, $F$, are measured (Fig. 8). The elastic coefficient is deduced from the slope of the linear part of the force-displacement curve. The coefficients can be compared with the values obtained by the theory of the homogenization:

$$
\begin{gathered}
C_{t t}=\frac{E_{\mathrm{wire}} S_{\mathrm{wire}}}{l_{\mathrm{rod}}} \\
C_{r r}=\frac{E_{\mathrm{rod}} S_{\mathrm{rod}}}{l_{\mathrm{wire}}}
\end{gathered}
$$

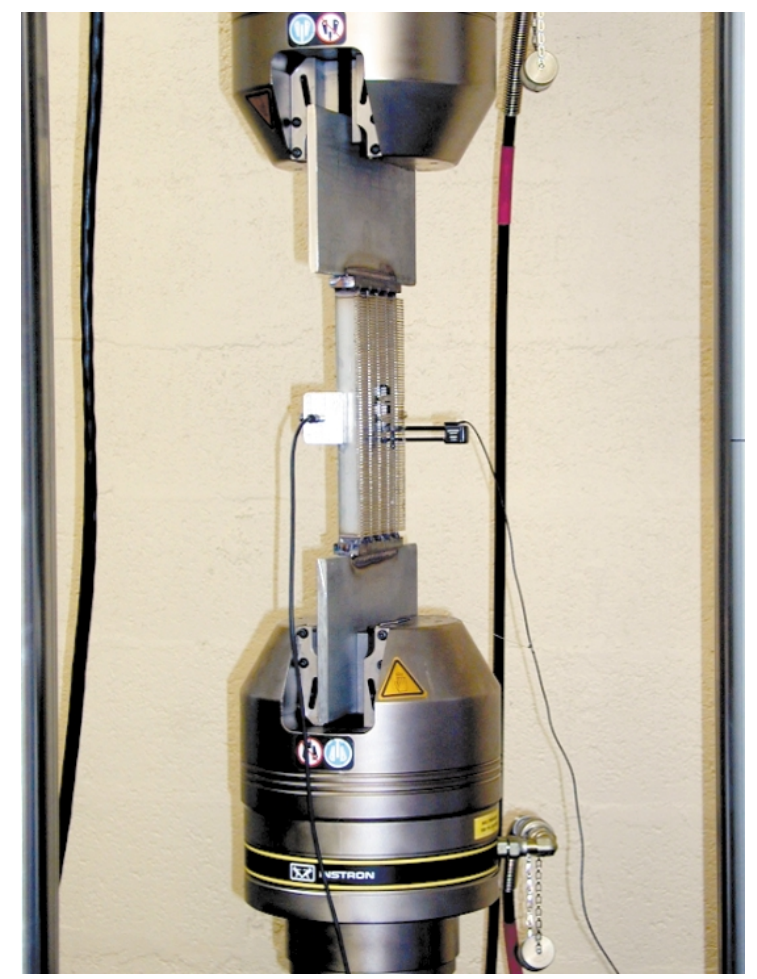

Figure 8

Experimental setting of the tension test
Tables 1 and 2 present the results obtained for a sample made of rods and " 90 " wires. The values obtained from a numerical FEM analysis (ABAQUSTM [8]) are also reported in the tables. The numerical calculation included the grid discretized with anisotropic plate elements. Their constitutive equation was described by Equations (7) and (8). The experimental results corroborate pretty well the numerical values.

\section{TABLE 1}

Tension test in the wire direction (sample made of "90" wires and of 14 rods)

\begin{tabular}{c|c|c}
\hline $\begin{array}{c}\text { Number } \\
\text { of wires }\end{array}$ & $\begin{array}{c}C_{t t} \text { experimental } \\
\mathrm{MN} / \mathrm{mm}\end{array}$ & $\begin{array}{c}C_{t t} \text { numerical } \\
\mathrm{MN} / \mathrm{mm}\end{array}$ \\
\hline 20 & 0.273 & 0.351 \\
40 & 0.303 & 0.348 \\
80 & 0.319 & 0.364 \\
\hline
\end{tabular}

TABLE 2

Tension tests in the rod direction (sample made of " 90 " wire)

\begin{tabular}{c|c|c}
\hline $\begin{array}{c}\text { Number } \\
\text { of rods }\end{array}$ & $\begin{array}{c}C_{r r} \text { experimental } \\
\mathrm{MN} / \mathrm{mm}\end{array}$ & $\begin{array}{c}C_{r r} \text { numerical } \\
\text { en } \mathrm{MN} / \mathrm{mm}\end{array}$ \\
\hline 5 & 0.560 & 0.506 \\
10 & 0.517 & 0.460 \\
\hline
\end{tabular}

By using the reference Young modulus of $199000 \mathrm{MPa}$, theoretical Equations (10) and (11) yield:

$$
C_{t t}=0.379 \mathrm{MN} / \mathrm{mm} \text { and } C_{r r}=0.588 \mathrm{MN} / \mathrm{mm}
$$

We note also that the error between the experimental tests and the theory becomes less than $3 \%\left(C_{t t}=0.319 \mathrm{MN} / \mathrm{mm}\right.$ and $C_{r r}=0.531 \mathrm{MN} / \mathrm{mm}$ ) if the measured rod Young modulus $(180000 \mathrm{MPa})$ and a wire Young modulus of $170000 \mathrm{MPa}$ are used.

\subsubsection{Shear Behavior of a Johnson Grid}

The principle of the shear test is to place between the press clamps a sample of Johnson grid (Fig. 7b) and to move the bottom clamp vertically downward at a constant speed $(0.1 \mathrm{~mm} / \mathrm{min})$ whereas the upper clamp stays motionless. The displacement, $\delta$, and the applied force, $F$, are measured (Fig. 9).

The test samples were designed to transform a global tension into a shearing. For that purpose, the steel plates needed for the sample fixation with the clamps of the testing machine must be much stiffer than the grids (Fig. 7b). A FEM numerical modeling of this test, thanks to the ABAQUS ${ }^{\mathrm{TM}}$ code, showed that the grid sample underwent a simple shearing. Figure 10 presents the banded contour plot of the vertical displacement in the sample and allows to verify the homogeneity of the test. 


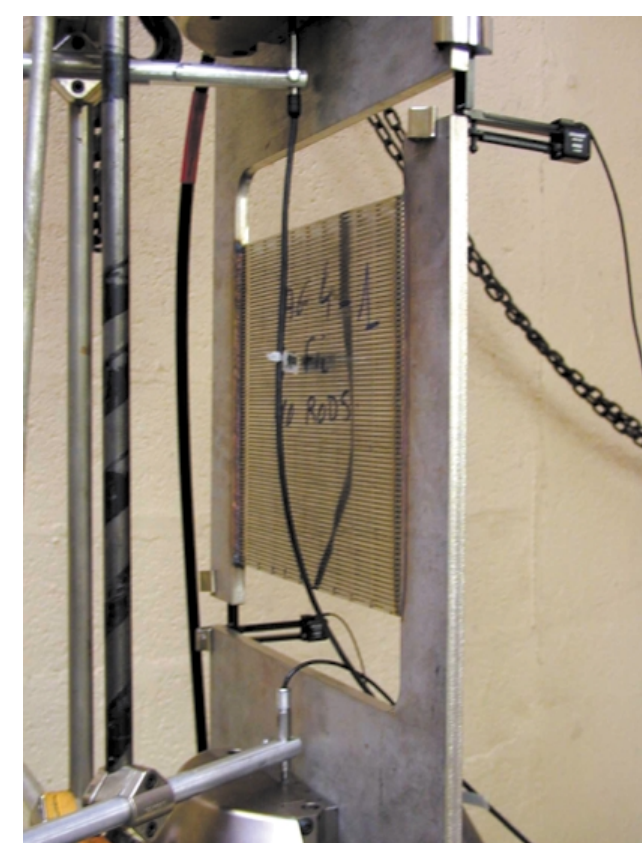

Figure 9

Experimental setting of the shear test.
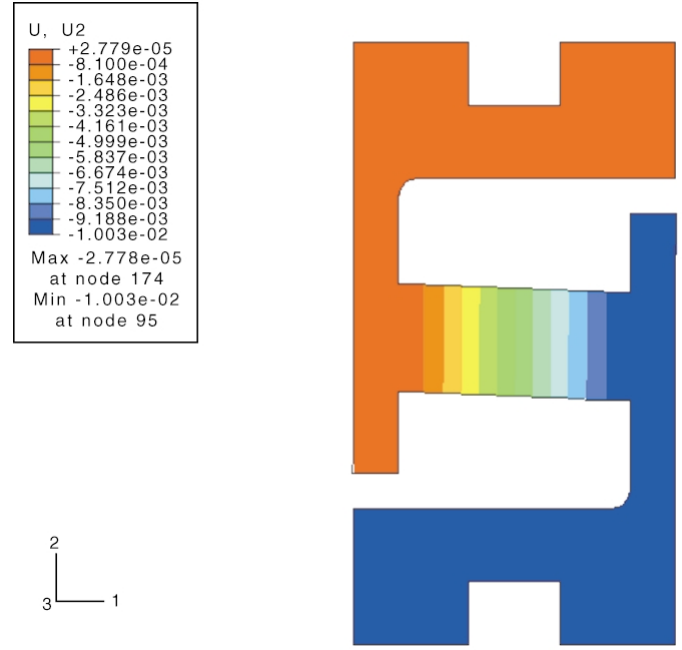

Figure 10

Shear test. Banded contour plot of the vertical displacement obtained from a FEM analysis.
The slope of the linear part of the force-displacement curve (Fig. 11) is linked to the elastic coefficient $C_{t r}$. In Table 3, the experimental value of $C_{t r}$ is compared, for samples made of " 90 " wires, with the theoretical value derived from Equation (9), and with the value given by the FEM calculation.

A significant difference appears between the experimental coefficient $C_{t r}$, valued from $827 \mathrm{~N} / \mathrm{mm}$ to $923 \mathrm{~N} / \mathrm{mm}$, and the theoretical coefficient $C_{t r}$ of $1880 \mathrm{~N} / \mathrm{mm}$ or the numerical one, valued from $1800 \mathrm{~N} / \mathrm{mm}$ to $2190 \mathrm{~N} / \mathrm{mm}$.

To explain the gap between test and model, the welding between rod and wire must be closely investigated. Indeed, the model considers that wires and rods are clamped together at their neutral fibers. However, at the scale of the threedimensional assemblage, Figure 12a shows a sharp shift of the clamping from the neutral fibers. So, the model stiffens the grid for the shear mode. To get a better approximation of the real grid, it is necessary to replace the rigid wire-rod connection by a spiral spring connecting the wire to the rod. A FEM computation for a shear load was carried out for the three-dimensional pattern (wire-rod assemblage) shown on Figure 12a. As pointed out by Figure 12b, the stress distribution along the rod axis is not linear through the beam section. Euler-Bernoulli hypothesis, which leads to linear normal stress over the beam section, is no more verified.

By expressing a new hypothesis on the stress distribution over the beams section, a better approximation for the shear coefficient would be found out. However, the real loadings applied to panels in a reactor are essentially bending and pressure. Therefore, the grid will be very weakly loaded in shearing mode. So, the precision on the coefficient $C_{t r}$ is strongly believed to have a minor importance within the framework of this study.

\subsubsection{Bending Behavior of a Johnson Grid}

To obtain the characteristics $D_{t t}, D_{r r}, D_{t r}$ of the plate equivalent to a grid, a test named 4-points bending test was set up. The principle of this test is depicted in Figure 13. The normal displacement of the plate was measured, on one hand, between superior rollers and the bed-plate $\left(\delta_{1}\right)$ and, on the other hand, between the bed-plate and the center of the lower face of the grid $\left(\delta_{2}\right)$ (Fig. 13). The experimental assembly is presented in Figure 14. The advantage of the setting consists in the constant moment zone created between both central rollers (spaced out by a length $a$ ) along the rollers direction.

TABLE 3

Shear tests on grids. Comparison between the numerical and experimental results

\begin{tabular}{c|c|c|c|c|c}
\hline Displacement direction & Number of wires & Number of rods & $C_{t r}$ experimental N/mm & $C_{t r}$ numerical N/mm & $C_{t r}$ analytical N/mm \\
\hline Rod & 40 & 10 & 853 & 1760 \\
Rod & 80 & 10 & 801 & 1880 \\
Wire & 80 & 10 & 923 & 1880 \\
\end{tabular}




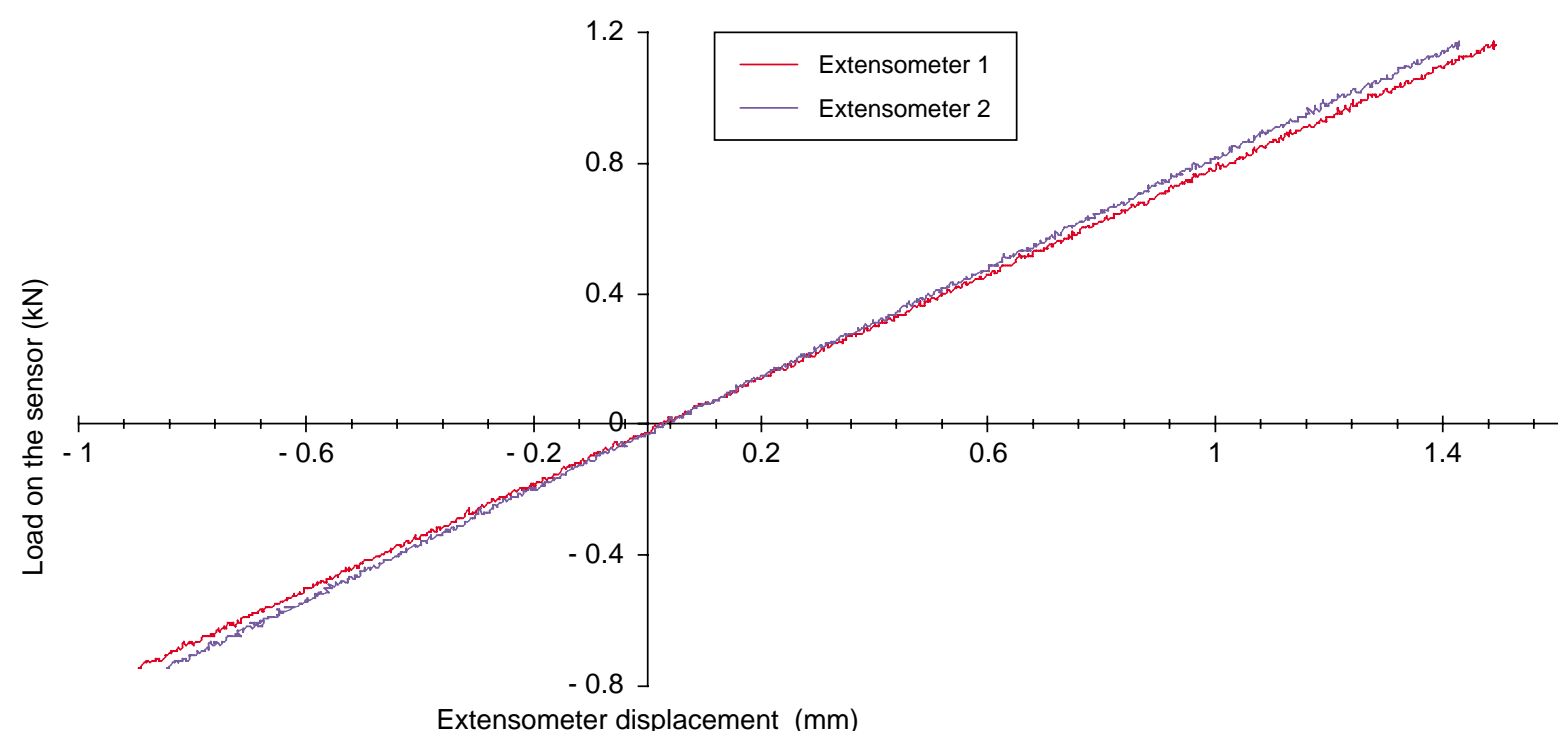

Figure 11

Shear test on a grid sample. Experimental force - displacement curve.
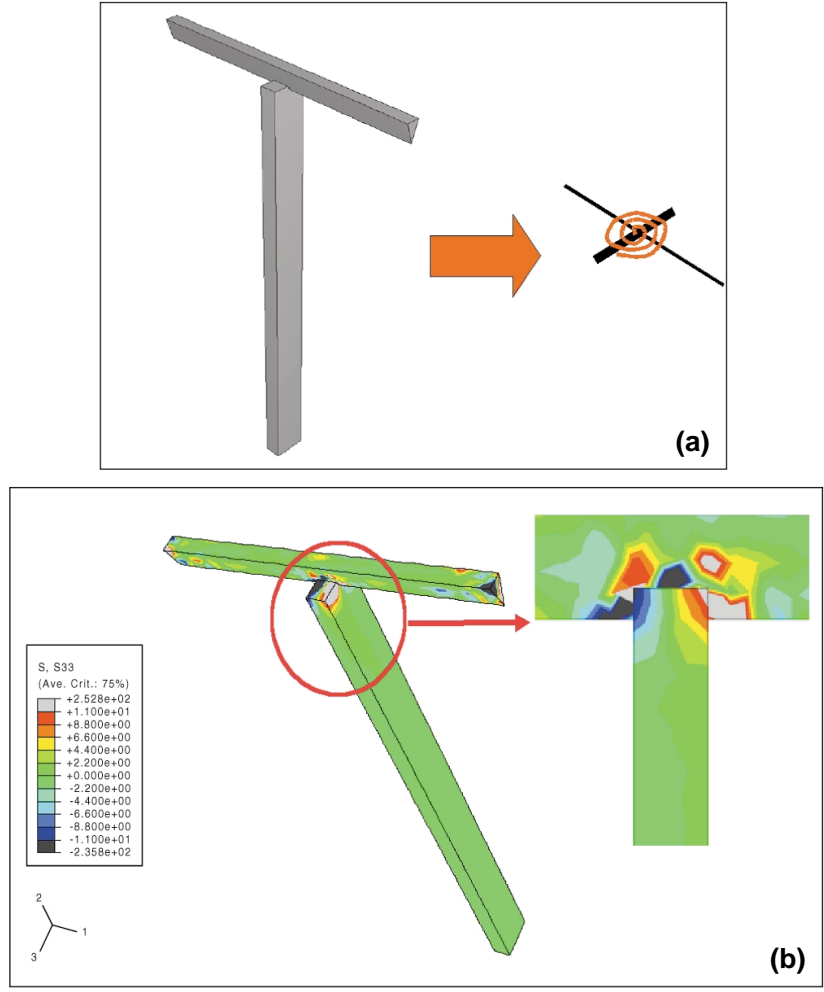

Figure 12

FEM analysis of the wire-rod connection.

a) sketch of the real wire-rod connection;

b) banded contour plot of the stress component along the axis of the rod under shear load.

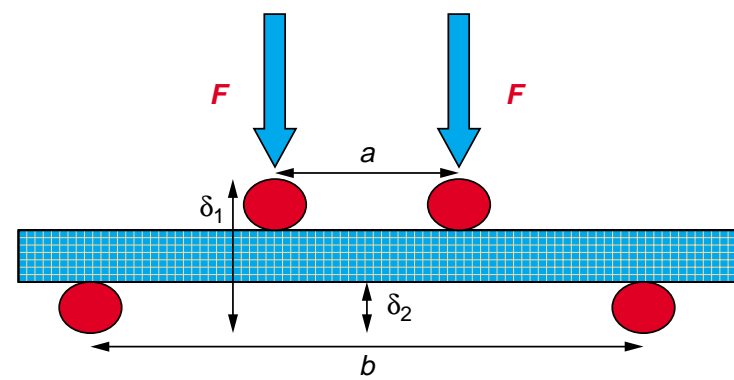

Figure 13

Principle of the four-points bending test. ( $a=400 \mathrm{~mm}$, $b=625 \mathrm{~mm}$ ).

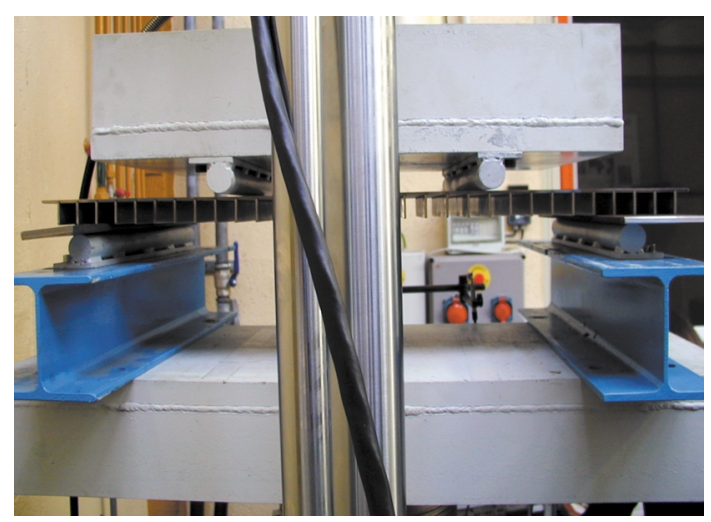

Figure 14

Test bench for four-points bending test on grids. 
The span between the outside rollers was $b=625 \mathrm{~mm}$, and the width of the tested grid is $L=300 \mathrm{~mm}$. The tests were also modeled using ABAQUSTM.

In the direction of the wires (respectively rods), the characterization of the bending behavior can be summarized by four-points bending of wires (respectively rods), put in parallel. Analytically, by applying classical mechanical engineering, the force applied on every roller is connected to the displacements $\delta_{1}$ and $\delta_{2}$ by the equations (where $d$ denotes the generic direction: $d=r$ for rod and $d=t$ for the wire):

$$
\begin{aligned}
& \delta_{1}=\frac{F}{48 D_{d d} L}(a-b)\left(a^{2}-2 a b-2 b^{2}\right) \\
& \delta_{2}=\frac{F}{24 D_{d d} L}(a-b)^{2}(b+2 a)
\end{aligned}
$$

In the particular case of the anisotropic material equivalent to the grid, by quoting $M_{d d}$ the central moment and $\kappa_{d d}$ the central curvature, the equation of the constitutive equation is:

with

$$
M_{d d}=D_{d d} \kappa_{d d}
$$

$$
\begin{aligned}
& M_{d d}=F \frac{(b-a)}{2 L} \\
& \kappa_{d d}=\frac{8\left(\delta_{2}-\delta_{1}\right)}{a^{2}}
\end{aligned}
$$

and the elastic coefficient in these directions is:

$$
D_{d d}=\frac{F a^{2}(b-a)}{16 L\left(\delta_{2}-\delta_{1}\right)}
$$

The coefficients experimentally obtained for the bending in the "90" wire direction and in the rod direction are: $D_{r r}=$ $26.4 \mathrm{kN} / \mathrm{m}$ and $D_{t t}=2 \mathrm{kN} / \mathrm{m}$. The tests on the $300 \mathrm{~mm}$ over $625 \mathrm{~mm}$ plate were numerically reproduced by using ABAQUS ${ }^{\mathrm{TM}}$. The calculated values $D_{r r}=23.2 \mathrm{kN} / \mathrm{m}$ and $D_{t t}=1.75 \mathrm{kN} / \mathrm{m}$ are in good agreement with the experiment.

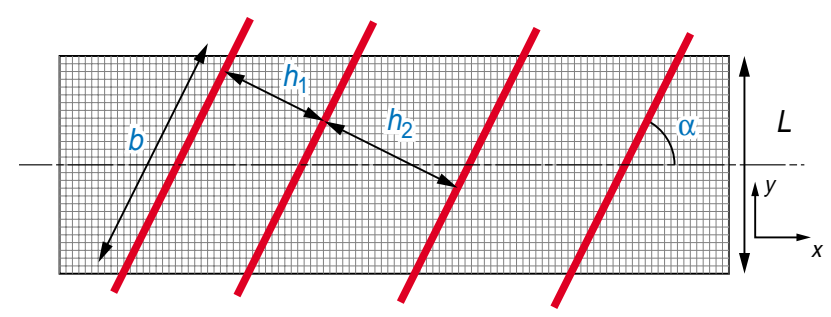

Figure 15

Principle of a four-points bending test on grid arranged obliquely with regard to rollers.
The validation of the theoretical coefficient $D_{t r}$ is more delicate. For that reason, a special test is performed where the grid is arranged in an oblique way. Figure 15 summarizes the sketch of the test. The slope of rollers with regard to the direction of the wires or the rods was $7^{\circ}$. The tests were calculated with ABAQUS ${ }^{\mathrm{TM}}$ by using the model of anisotropic equivalent plate for the grid with the coefficients $D_{r r}, D_{t t}$ and $D_{t r}$ obtained from Relations (9). To compare the results of the experiment to those of the calculation, a rigidity $K_{\text {bend }}$ is defined by the ratio $2 F /\left(\delta_{2}-\delta_{1}\right)$. Table 4 reports the concordant numerical and experimental results.

TABLE 4

Synthesis of the results for the four points bending test on a grid arranged obliquely with regard to rollers

\begin{tabular}{c|c|c|c}
\hline $\begin{array}{c}\text { Oblique } \\
\text { bending }\end{array}$ & $\begin{array}{c}K_{\text {bend }} \\
\text { expérimental } \\
\mathrm{N} / \mathrm{mm}\end{array}$ & $\begin{array}{c}K_{\text {bend }} \\
\text { numerical } \\
\mathrm{N} / \mathrm{mm}\end{array}$ & Gap \\
\hline $\begin{array}{c}\text { Oblique with } \\
7.3^{\circ} \text { compared to wires }\end{array}$ & 497.8 & 554.0 & $11.31 \%$ \\
\hline $\begin{array}{c}\text { Oblique with } \\
7.3^{\circ} \text { compared to rods }\end{array}$ & 7304.9 & 6333.1 & $-13.30 \%$ \\
\hline
\end{tabular}

\subsubsection{Conclusion on the Johnson Grid Model}

The agreement with the theory of homogenization is satisfactory except for the case of the shearing. There, the proposed model must be improved by the addition of a spiral spring among the wires and the rods. This refinement was not taken into account since the shear stiffness has no influence on the calculation of a reactor which involves only pressure and bending loads applied to the outer basket.

\section{STRUCTURAL TESTS}

Two kinds of structural test were performed. A series of crushing tests consists in setting a panel under a uniform compression, via the Johnson grid. The second series of tests consists in performing four-points bending tests on a panel.

Figure 16 indicates the geometry of the right section of the cylindrical panel used in the tests. This section is a trapezium whose height is $d_{h}=167 \mathrm{~mm}$ and whose width is $d_{w}=230 \mathrm{~mm}$ for the fenced face (or panel roof). The radius $R$ of the bottom of panel is $1475 \mathrm{~mm}$. To build these panels, $5 \mathrm{~mm}$ thick steel sheets are used.

\subsection{Panel Crushing Test}

Two crushing tests were run on $60 \mathrm{~cm}$ long panels. A test consisted in applying a load uniformly distributed over the Johnson grid of the panel. The bottom of the panel lied on a fixed wall. The wall took the exact cylindrical shape of the 


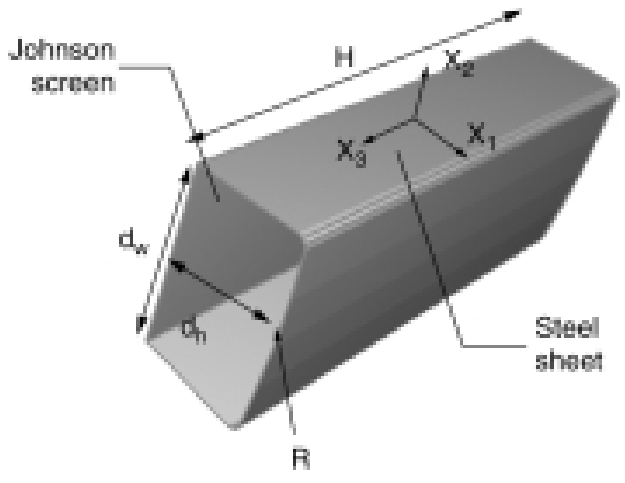

Figure 16

Geometry of the tested panel.

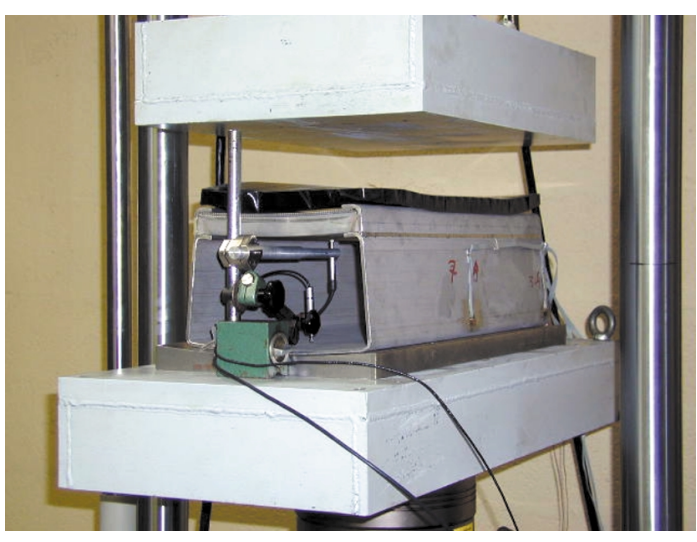

Figure 17

Experimental setting of the panel crushing test. panel bottom (curvature radius of $1.475 \mathrm{~m}$ ). The experimental device is described in Figure 17: the load was distributed on the grid thanks to a flexible pillow which took the exact cylindrical shape of the grid and tried to ensure the uniformity of the applied load.

The specific test bench was set between the clamps of the INSTRON $8500+$ press. The press applied a $2 \mathrm{kN} / \mathrm{min}$ regular load rate. The load cell of the press measured the value of the applied force.

The panel was instrumented with strain gauges on its internal and outside steel sheets to measure localized strains.

Two LVDT displacement sensors were fixed on the panel. The first one arranged under the grid supplied the displacement $\delta_{1}$ of the roof. The second one supplied the displacement $\delta_{2}$ of the panel bottom.

The panel test was computed with the ABAQUS ${ }^{\mathrm{TM}}$ code in which the homogenized constitutive equation of grid was injected. The FEM numerical result is compared with the experiment by using the rigidity $K_{c r}$ :

$$
K_{c r}=\frac{F}{\delta_{2}-\delta_{1}}
$$

where $F$ is the force applied on the panel. The test gave a 64.5 $\mathrm{MN} / \mathrm{mm}$ rigidity whereas the numerical computation gave $93 \mathrm{MN} / \mathrm{mm}$. The $30 \%$ relative gap is considered acceptable due to the uncertainty on the elastic modulus of rods and wires.

The numerical simulation also supplied the panel skin stress. Thanks to the Vishay strain gauges (CEA-06-125UT$120)$, the aptness of the numerical approach in very local points of comparison was confirmed.

Figure 18 shows the distribution of the FEM numerical normal displacement on the panel. From the computation, the unsticking of the panel bottom from the wall appears clearly: this was also established visually during the test.
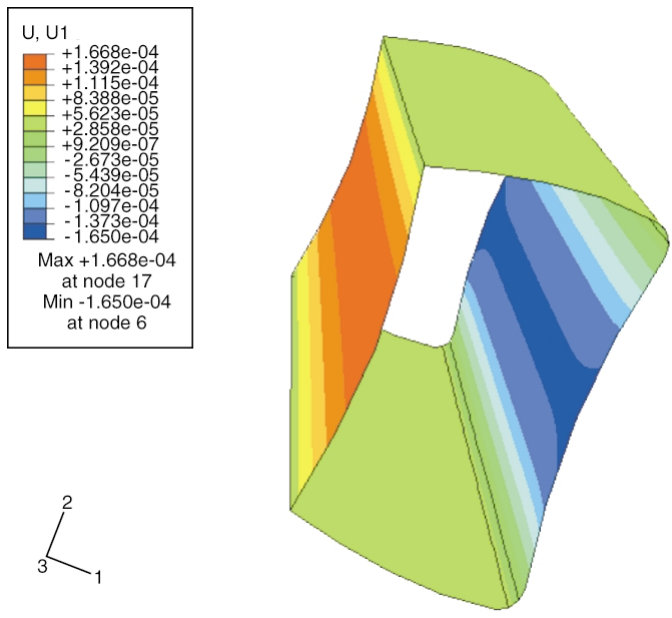

Figure 18

Distribution of the normal displacement (m) over the grid.

\subsection{Four-Points Bending of a Panel}

\subsubsection{Presentation of the Test}

A four-points bending test was performed on a $2 \mathrm{~m}$ long panel. Figure 19 shows an illustration of the experimental test bench. The principle of the test is the same as for the fourpoints bending test on a Johnson grid (Fig. 13), except for the shape of the rollers. The dimensions of the bench also changed, the load was applied incrementally by $20 \mathrm{~kg}$ weights (Fig. 19). The span between both outside rollers was $1700 \mathrm{~mm}$. The distance between an outside roller $(20 \mathrm{~mm}$ thick) and an internal roller was $620 \mathrm{~mm}$ while the distance between both central rollers was $300 \mathrm{~mm}$. Strain gauges were positioned on the internal and steel sheet of the panel. 


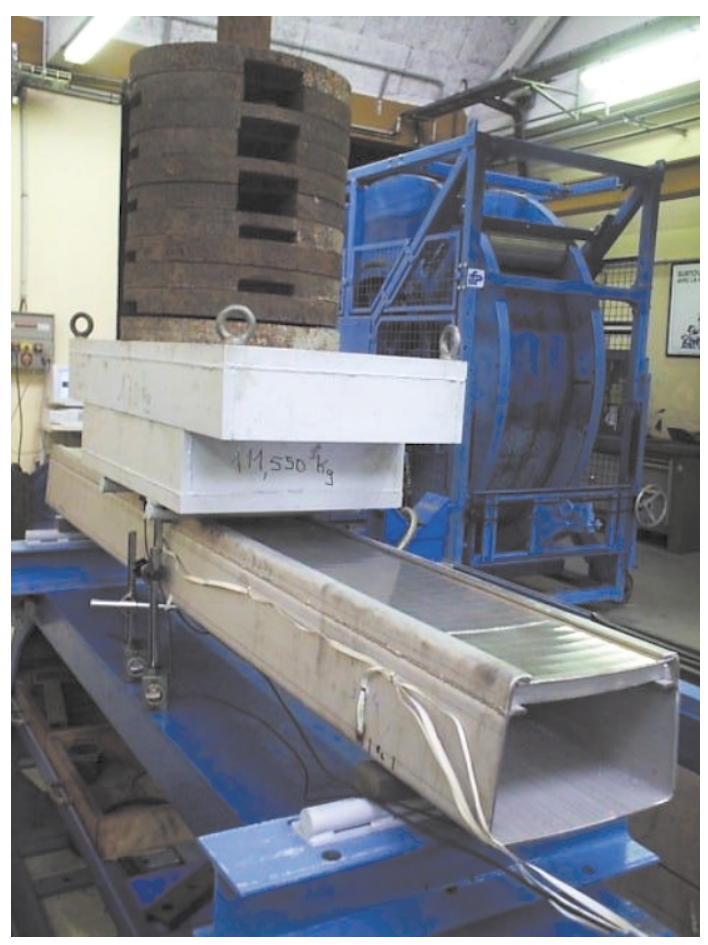

Figure 19

Experimental setting of the four-points bending test on panel.

Two LVDT displacement sensors were settled to measure the grid displacement in the center of the panel and the deflection of the panel bottom facing the other sensor. It was verified that the global deformation of the overall structure was negligible during the test.

\subsubsection{Comparisons between the Experimental and Numerical Results}

For the numerical FEM calculation, the panel was only meshed between the rollers.

The stiffness $K_{\text {flex }}=2 F / \delta_{2}$ is used to compare the experiment to the calculation ( $F$ is the force applied on every roller and $\delta_{2}$ is the displacement of the panel bottom).

The experimentally obtained stiffness is $12,7 \mathrm{MN} / \mathrm{mm}$ while the calculation supplies $14.6 \mathrm{MN} / \mathrm{mm}$.

The banded contour plot of the Von Mises stress for an applied load of $1054 \mathrm{~N}$ on each central roller (equivalent to a 0.224 MPa pressure on the rollers) is drawn in Figure 20. The maximum stress is spotted on the outside rollers (indicated by arrows in Figure 20) at the fillet fitted out to connect the panel bottom with the panel sides. A lever effect created by the radius of the fillet is responsible for this stress localization.

Figure 21 represents the evolution of the numerical deflection along the length of the panel on the central line of the grid and on the central line of the panel bottom.

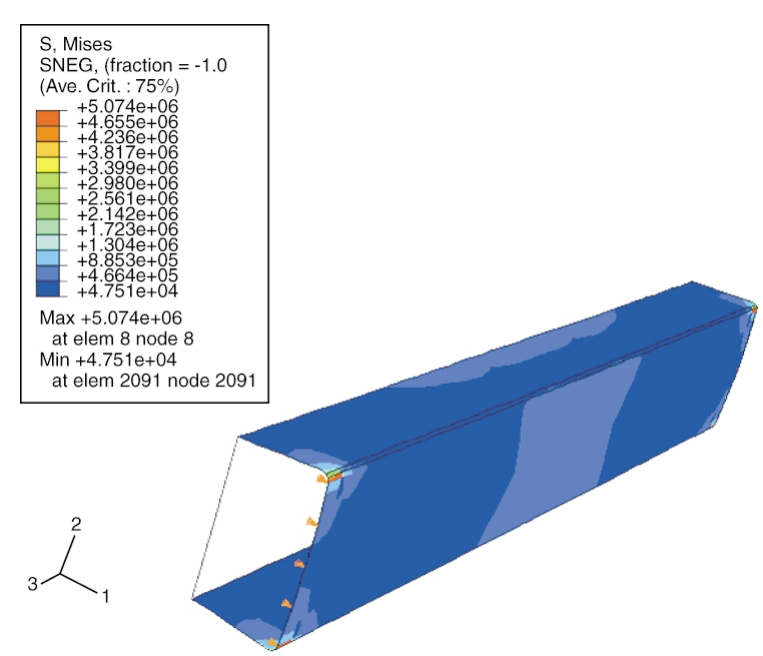

Figure 20

Mapping of Von Mises stress $(\mathrm{Pa})$ on a 100 times amplified deformed mesh.

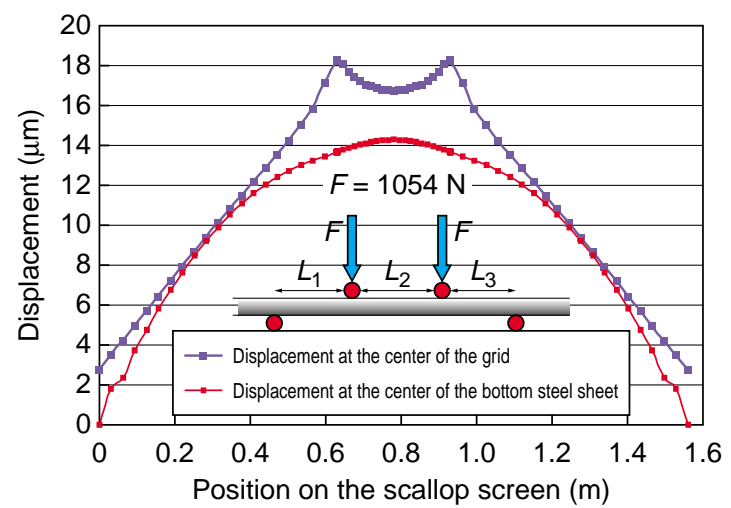

Figure 21

Numerical deflections along the panel on the central axis of the roof (grid part) and on the central axis of the bottom.

The distribution of deflection along the width of the grid is nonuniform: this emphasizes the anisotropy of the grid.

\subsection{Synthesis on the Structural Tests}

The anisotropic plate model developed for a Johnson grid, integrated into a FEM software for structure calculation, gives an acceptable representation of the behavior of one OptiMiser ${ }^{\mathrm{TM}}$ panel. The numerical modeling generally supplies stiffness coefficients higher than those obtained from the experiments. The observed disparity remain however reasonable. Moreover they would have been smaller if the Young modulii of the wires and the rods, measured in laboratory, were kept. 


\section{CONCLUSION}

This study delivers the experimental and numerical validation of a new concept of outer basket, called OptiMiser $^{\mathrm{TM}}$, developed by Johnson for the reactors of catalytic reforming. This basket is modular and constituted by a vertical setting of panels put side by side to contain the catalyst in the reactor. One panel is a composite assemblage of steel sheet and Johnson grid. Thanks to this study, a realistic modeling of elastic behavior has been developed for a panel.

A first step consisted in developing a model of anisotropic plate equivalent to a Johnson grid by using a theory of homogenization from a basic pattern of the grid. This model was compared to the results of mechanical tests performed on Johnson grid samples: tension, shearing and bending. The elastic characteristics obtained by the theory are close to those supplied by the tests of tension and bending. The predictions would be improved if the wires and rods elastic modulii measured in laboratory were taken into account, in place of the steel modulus recommended by ASME. On the other hand, a disagreement remains between the theory and the experiment in the case of shearing: the theoretical modulus is much stronger than the experimental modulus. The gap has been explained by the theoretical simplification upon the wire-rod connection: this does not take into account the thickness of the welding and the corresponding gap between the neutral fibers of the wires and the rods. However, it has been considered that it is not useful to improve the model regarding its shearing part since the error on stiffness has no influence on the calculation of the reactor when a real loading is applied (bending and normal pressure on the outer basket).

A second step allowed to verify that the equivalent anisotropic plate model developed could be effectively used in a finite element modeling of the panel.

Uniform compression and four-points bending structural tests were performed on large length panels. The comparison between the experimental results and the numerical computations confirms more completely the developed elastic modeling.
Therefore, the elastic modeling of a Johnson grid by an equivalent homogeneous anisotropic plate can be used for the engineering of the new type of panel for catalytic reforming reactors.

The provided study is an interesting start to develop a useful theory in order to foresee the behavior of this kind of structure when irreversible strains arise.

So, it should be possible to take completely advantage of the modular concept of the basket OptiMiser ${ }^{\mathrm{TM}}$ for the building of reactor internals and for the operations of maintenance.

\section{ACKNOWLEDGEMENTS}

We are indebted to Anne Guisen, Roger Hébert, Guy Pignard who conducted the experimental part of the study at the Centre d'essais mécaniques des Noisetiers, Institut français du pétrole.

\section{REFERENCES}

1 Johnson (1994) Industrial Filters Brochure.

2 Moreau, G. and Caillerie, D. (1998) Continuum Modelling of Lattice Structures in Large Displacement-Application to Buckling Analysis, Computers and Structures, Special issue, Topping BHV, Ed., 68, 181-189.

3 Pradel, F.(1998) Homogénéisation des milieux discrets périodiques orientés. Une application aux mousses, $P h D$ Thesis, Ecole nationale des ponts et chaussées, France.

4 Sanchez-Hubert, J. and Sanchez-Palencia, E (1992) Introduction aux méthodes asymptotiques et à l'homogénéisation, Masson.

5 Timoshenko, S. and Woinowsky-Krieger, S. (1959) Theory of Plates and Shells, Mc Graw-Hill.

6 Pradel, F. and Sab, K. (1998) Cosserat Modelling of Periodic Lattice Structures. C. R. Acad. Sci. IIb, 326, 699-704.

7 Caillerie, D. (1984) Thin Elastic and Periodic Plates. Math. Meth. in Appl. Sciences, 6, 159-161.

8 Hibbitt, Karlsson and Sorensen, Inc. (1998) ABAQUS TM/ Standard User's Manual Version 5.8, II \& III.

Final manuscript received in October 2001 